\title{
Effect of Arbuscular Mycorrhizal Fungus Inoculation on Growth of Sandersonia
}

\author{
Yoh-ichi MATSUBARA and Satoko SAKURAI \\ Faculty of Agriculture, Gifu University, Gifu 501-1193, Japan
}

\begin{abstract}
The means of inoculation with arbuscular mycorrhizal(AM) fungi[ Gigaspora margarita (GM), Glomus aggregatum (ga), Glomus fasciculatum (gf), Glomus mosseae (gm)] were investigated in sandersonia (Sandersonia aurantiaca Hook.).

Fifteen weeks after inoculation, AM fungal infection with the four fungal species occurred in all the inoculated plants. The infection level in a root system reached $51.6 \%$ in GM, $45.9 \%$ in gf, $39.4 \%$ in ga and $30.2 \%$ in gm. Shoot growth, plant height, no. of leaves and no. of flowers in AM fungus-inoculated plants were superior to those in noninoculated ones, the effect being relatively greater in GM and gf than in ga and gm. As for daughter tuber growth, both the length and maximum diameter of daughter tubers showed higher values in almost all AM fungus-inoculated plants than in noninoculated ones, the effect being more pronounced in GM and gm than in ga and gf. Dry weights of both shoots and daughter tubers were superior in AM fungus-inoculated plants. Formation of marble-shaped daughter tubers occurred in all the treatments, and the rate of such formation was higher in AM fungus-inoculated plants. An increase in $\mathrm{P}$ concentrations occurred in the shoots of AM fungus-inoculated plants, the effect being more pronounced in ga and gf than in GM and gm. On the other hand, in daughter tubers, no major difference appeared in $\mathrm{P}$ concentration among the treatments.

It was clarified that AM fungus infection and plant growth promotion through symbiosis occurred in sandersonia, and that AM fungus inoculation is effective in stimulating tuberization.
\end{abstract}

Keywords : arbuscular mycorrhizal fungi, sandersonia, symbiosis

\section{Introduction}

Sandersonia (Sandersonia aurantiaca Hook.), also known as Christmas bells or Chinese lantern lily, is a liliaceous tuber plant with small orange bell-shaped flowers ${ }^{1 \sim 3)}$. It occurs naturally in South Africa, and has become a major cut flower in Japan ${ }^{4 \sim 6)}$. During the growing season, the original tuber dies after producing usually two daughter tubers. In Japan, most of the original tubers are imported from New Zealand, and a more effective method of raising tubers has been required because of its high cost and long raising period ${ }^{4 \sim 7)}$. Recently, although tuber propagation via the tissue culture method has been attempt-

Received 3 August 1999

Accepted 20 November 1999 $\mathrm{ed}^{3,7,8)}$, it has not been successful to date, so that the problem remains of raising tissue culture-derived tubers to tubers with high flowering potential.

Infection with arbuscular mycorrhizal(AM) fungus has the effect of promoting host plant growth mainly by enhancing phosphorus uptake through symbiosis9). AM fungus inoculation in ornamental plants has been reported in cyclamen ${ }^{10)}$ and petunia ${ }^{11)}$. However, since there are no reports on AM fungus inoculation in sandersonia, it is unclear whether AM fungus infection and plant growth promotion through symbiosis occurr in that species, or how effective AM fungal symbiosis is in stimulating tuberization.

In this study, effect of AM fungus inoculation on growth of sandersonia was investigated using $4 \mathrm{AM}$ fungal species. 


\section{Materials and methods}

\section{AM fungus inoculation and plant cultivation}

Marble-shaped tubers of sandersonia (Sandersonia aurantiaca Hook.) were germinated in a moistened mixture of vermiculite and soil[autoclaved at $1.2 \mathrm{~kg}$ • $\mathrm{cm}^{-2}$ and $121^{\circ} \mathrm{C}$ for 1 hour; pH 5. 8-6.5 $\left(\mathrm{H}_{2} \mathrm{O}\right)$; available-P content, $21.9 \mathrm{mg} / 100 \mathrm{~g}$ dry soil], and then packed in plastic containers $[35 \mathrm{~cm} \times 50 \mathrm{~cm} \times 10 \mathrm{~cm}$ (H) ]. Three-week-old plants, $10 \mathrm{~cm}$ in height, were prepared for inoculation. Each plant root was inoculated with 1-gram of inoculum containing spores of Gigaspora margarita (GM), Glomus aggregatum (ga), Glomus fasciculatum (gf), Glomus mosseae (gm) obtained from commercial sources: spore densities were 20 spores $\cdot \mathrm{g}^{-1}$ inoculum in $\mathrm{GM}$, and unknown in the others. Inoculation was carried out by the method of Matsubara et al. ${ }^{12}$.

Bed soil of the same constituents as those used in tuber germination was packed in plastic containers [36 $\mathrm{cm} \times 30 \mathrm{~cm} \times 16 \mathrm{~cm}(\mathrm{H})$ ]into which AM fungus-inoculated plants were transplanted and raised in a greenhouse. Plants were watered adequately and fertilized with a mixed fertilizer $\left(\mathrm{N}: \mathrm{P}: \mathrm{K}=8: 3: 10,0.5 \mathrm{~g} \cdot l^{-1}\right.$ soil). Eight plants per treatment were used.

Observation of AM fungal infection and evaluation of AM fungal infection level in roots

Fifteen weeks after inoculation, AM fungal infection in the roots was observed by a staining procedure according to Phillips and Hayman ${ }^{13)}$. In addition, the rate of AM fungus-infected segments in whole lateral roots (abbreviated RFISL; expressed as the percentage of $1-\mathrm{cm}$ AM fungus-infected segments in $1-\mathrm{cm}$ segments of the whole lateral root)was recorded. RFISL was calculated by averaging the values of three plants.

\section{Determination of phosphorus in plants}

Plants for determining $\mathrm{P}$ were sampled fifteen weeks after AM fungus inoculation. $P$ concentrations in those plants were determined by the method of Matsubara and Harada ${ }^{14)}$.

\section{Results}

The period for the induction of first flower bud was shorter in AM fungus-inoculated plants; no significant

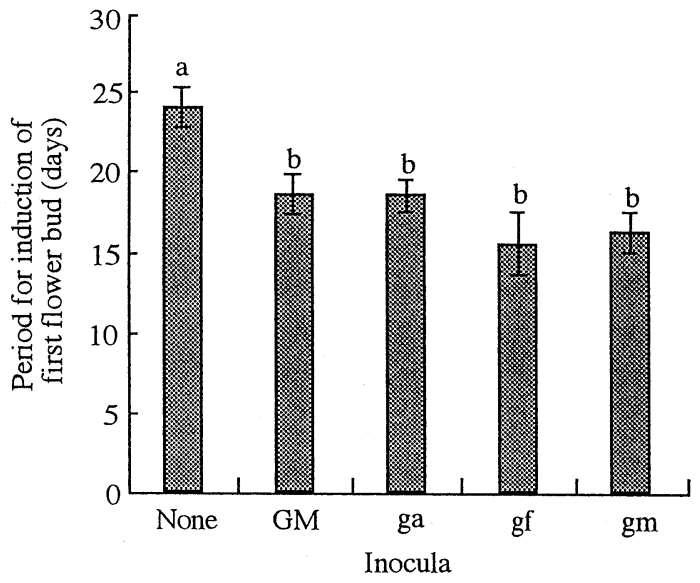

Fig. 1 Effect of AM fungus inoculation on period for induction of first flower bud in sandersonia.

None, noninoculated; GM, inoculated with Gigaspora margarita; ga, inoculated with Glomus aggregatum; gf, inoculated with Glomus fasciculatum, gm, inoculated with Glomus mosseae. Data were recorded 15 weeks after inoculation. Different letters represent significantly different values according to Duncan's multiple range test at $5 \%$ level. Vertical bars represent standard error.

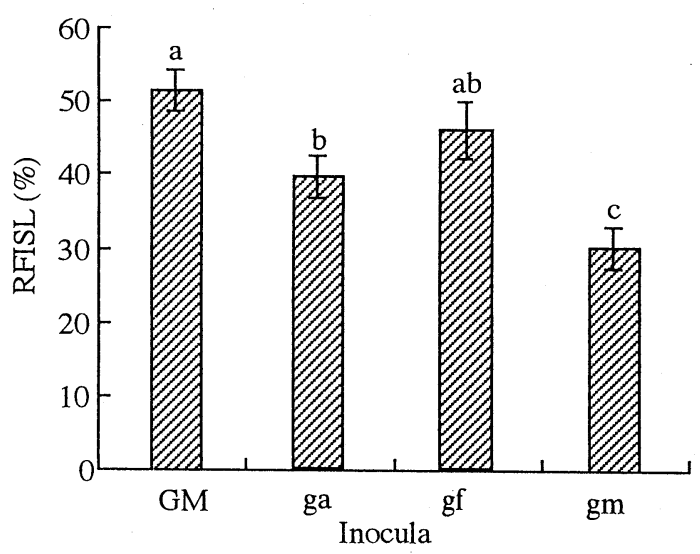

Fig. 2 Rate of AM fungus-infected segments in whole lateral roots(abbreviated RFISL) 15 weeks after AM fungus inoculation. GM, inoculated with Gigaspora margarita; ga, inoculated with Glomus aggregatum; gf, inoculated with Glomus fasciculatum; gm, inoculated with Glomus mosseae. Different letters represent significantly different values according to Duncan's multiple range test at $5 \%$ level. Vertical bars represent standard error. 


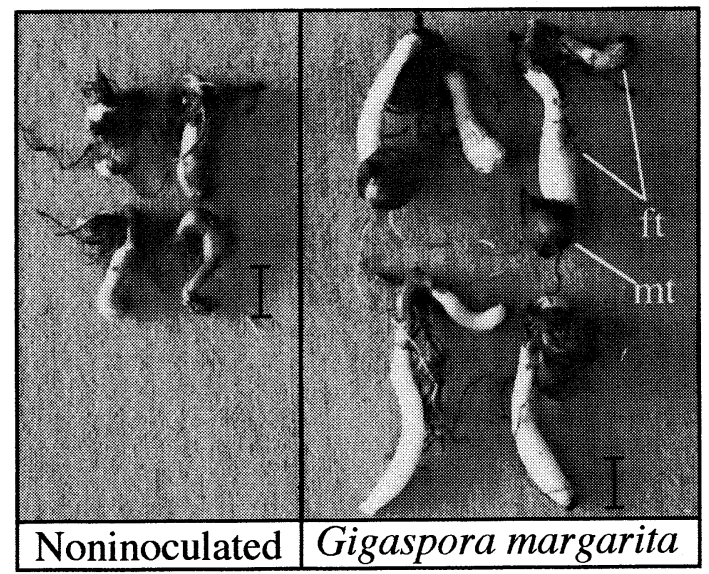

Fig. 3 Effect of AM fungus inoculation on daughter tuber development in sandersonia(15weeks after inoculation).

$\mathrm{ft}$, fork-shaped tuber; $\mathrm{mt}$, marble-shaped tuber.

Scale bars represent $1 \mathrm{~cm}$.

difference appeared among the fungal species(Fig. 1).

Fifteen weeks after inoculation, AM fungal infection occurred in all the inoculated plants, irrespective of the fungal species(Fig. 2). The infection level in a root system reached $51.6 \%$ (maximum) in GM, 30. $2 \%$ (minimum) in gm; it showed relatively higher values in GM, ga and gf than in gm. Shoot growth, plant height, no. of leaves and no. of flowers in AM fungus -inoculated plants were greater than in noninoculated ones, the effect being relatively greater in GM and gf than in ga and gm(Table. 1). As for daughter tuber growth, fork-shaped daughter tubers were formed in all the treatments. The length and maximum diame- ter of daughter tuber increased more in almost all AM fungus-inoculated plants, the effect being more pronounced in GM and gm than in ga and gf (Table 1 and Fig. 3). Marble-shaped daughter tubers formed in all the treatments, and the rate of formation gave higher values in AM fungus-inoculated plants, reaching 75\% (maximum) in gm, while in noninoculated plants it reached only $25 \%$ (minimum). The dry weight of both shoots and daughter tubers were superior in AM fungus-inoculated plants compared with noninoculated ones, and the difference among the fungal species was more marked in daughter tuber rather than in shoots(Fig. 4). As for daughter tuber weight, GMand gm-inoculated plants showed considerably higher values than noninoculated ones, and no significant difference was observed between GM and gm or ga and gf.

$\mathrm{P}$ concentrations in shoots were higher in AM fungus-inoculated plants, the effect being more pronounced in ga and gf than in GM and gm. On the other hand, in daughter tubers, no major difference appeared in $\mathrm{P}$ concentrations among the treatments (Fig. 5).

\section{Discussion}

This study confirmed that AM fungal infection and symbiosis occurred in sandersonia with 4 fungal species, and such symbiosis led to the promotion of flowering, an increase in the no. of flowers, and prominent development in daughter tubers; the effect differed with fungal species. Takenaga et al. ${ }^{10)}$ re-

Table 1 Effect of AM fungus inoculation on growth of sandersonia ${ }^{z}$

\begin{tabular}{|c|c|c|c|c|c|c|c|c|}
\hline \multirow{2}{*}{$\begin{array}{l}\text { AM fungus } \\
\text { inoculation }^{y}\end{array}$} & \multirow{2}{*}{$\begin{array}{l}\text { Plant } \\
\text { height }^{\mathrm{x}} \\
\text { (cm) }\end{array}$} & \multirow{2}{*}{$\begin{array}{l}\text { No. of } \\
\text { leaves }^{x}\end{array}$} & \multirow{2}{*}{$\begin{array}{c}\text { Diameter } \\
\text { of shoots } \\
(\mathrm{mm})\end{array}$} & \multirow{2}{*}{$\begin{array}{l}\text { No. of } \\
\text { flowers } \\
\text { (/plant) }\end{array}$} & \multicolumn{2}{|c|}{$\begin{array}{c}\text { Length of } \\
\text { daughter tuber }\end{array}$} & \multirow{2}{*}{$\begin{array}{l}\text { Maximum } \\
\text { diameter of } \\
\text { daughter tuber } \\
(\mathrm{mm})\end{array}$} & \multirow{2}{*}{$\begin{array}{c}\text { Rate of } \\
\text { marble-shaped } \\
\text { tuber formation } \\
(\%)\end{array}$} \\
\hline & & & & & $\begin{array}{c}1 \\
(\mathrm{~cm})\end{array}$ & $\begin{array}{c}2 \\
(\mathrm{~cm})\end{array}$ & & \\
\hline None & $51.4 \pm 1.1 \mathrm{c}^{\mathrm{u}}$ & $27.4 \pm 1.0 \mathrm{c}$ & 1. $84 \mathrm{a}$ & $3.3 \pm 0.2 \mathrm{c}$ & $1.9 \pm 0.1 \mathrm{~d}$ & $1.0 \pm 0.1 \mathrm{c}$ & $5.11 \pm 0.11 d$ & 25.0 \\
\hline GM & $78.4 \pm 3.2 \mathrm{a}$ & $38.8 \pm 1.4 \mathrm{a}$ & 1. $84 \mathrm{a}$ & $5.7 \pm 1.0 \mathrm{ab}$ & $4.4 \pm 0.3 a$ & $2.8 \pm 0.2 \mathrm{a}$ & $8.37 \pm 0.13 a$ & 50.0 \\
\hline ga & $68.2 \pm 2.9 \mathrm{~b}$ & $31.2 \pm 3.3 \mathrm{bc}$ & 1. $84 \mathrm{a}$ & $4.6 \pm 0.3 \mathrm{~b}$ & $2.0 \pm 0.2 \mathrm{~cd}$ & $1.9 \pm 0.1 \mathrm{~b}$ & $7.01 \pm 0.48 \mathrm{~b}$ & 50.0 \\
\hline gf & $78.4 \pm 3.0 \mathrm{a}$ & $38.0 \pm 0.9 \mathrm{a}$ & $1.86 \mathrm{a}$ & $7.0 \pm 0.5 \mathrm{a}$ & $2.5 \pm 0.3 \mathrm{bc}$ & $1.3 \pm 0.5 b c$ & $6.32 \pm 0.15 c$ & 37.5 \\
\hline $\mathrm{gm}$ & $68.6 \pm 2.2 \mathrm{~b}$ & $37.5 \pm 3.1 \mathrm{ab}$ & $1.84 \mathrm{a}$ & $5.2 \pm 1.4 \mathrm{ab}$ & $3.0 \pm 0.2 \mathrm{~b}$ & $2.7 \pm 0.1 \mathrm{a}$ & $7.81 \pm 0.32 b$ & 75.0 \\
\hline
\end{tabular}

${ }^{2}$ Data were collected 15 weeks after inoculation from 8 plants.

${ }^{y}$ None, noninoculated; GM, inoculated with Gigaspora margarita; ga, inoculated with Glomus aggregatum; gf, inoculated with Glomus fasciculatum; gm, inoculated with Glomus mosseae.

${ }^{x}$ Mean \pm S.E.

"Expressed on fork-shaped daughter tubers following the tuber which is maximum in length.

"Ratio of marble-shaped tuber formed plants to total plants.

'Mean separation within columns by Duncan's multiple range test at $5 \%$ level. 


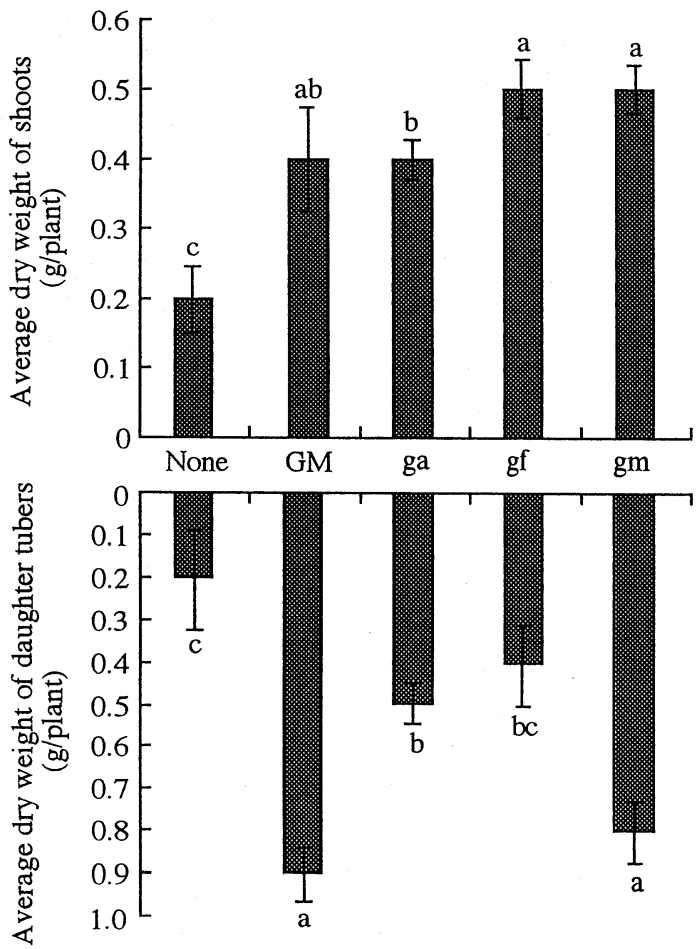

Fig. 4 Effect of AM fungus inoculation on dry weight of sandersonia.

None, noninoculated; GM, inoculated with Gigaspora margarita; ga, inoculated with Glomus aggregatum; gf, inoculated with Glomus fasciculatum, gm, inoculated with Glomus mosseae. Data were recorded 15 weeks after inoculation. Different letters represent significantly different values according to Duncan's multiple range test at 5\% level. Vertical bars represent standard error.

ported that in cyclamen, an infection with Glomus mosseae increased the no. of leaves and flowers. The same phenomena were also recognized in this experiment with sandersonia. Our results indicated that AM fungus inoculation is effective in obtaining vigorous plants which have a high flowering potential, and in stimulating tuberization which leads to shortening tuber raising period.

It is reported that in sandersonia, plant height and no. of flowers were proportioned to planted tuber weight regardless of tuber shape ${ }^{1,5,6)}$. In this study, AM fungal infection enhanced plant growth and daughter tuber development, and increased the no. of flowers, even using small, marble-shaped tubers.

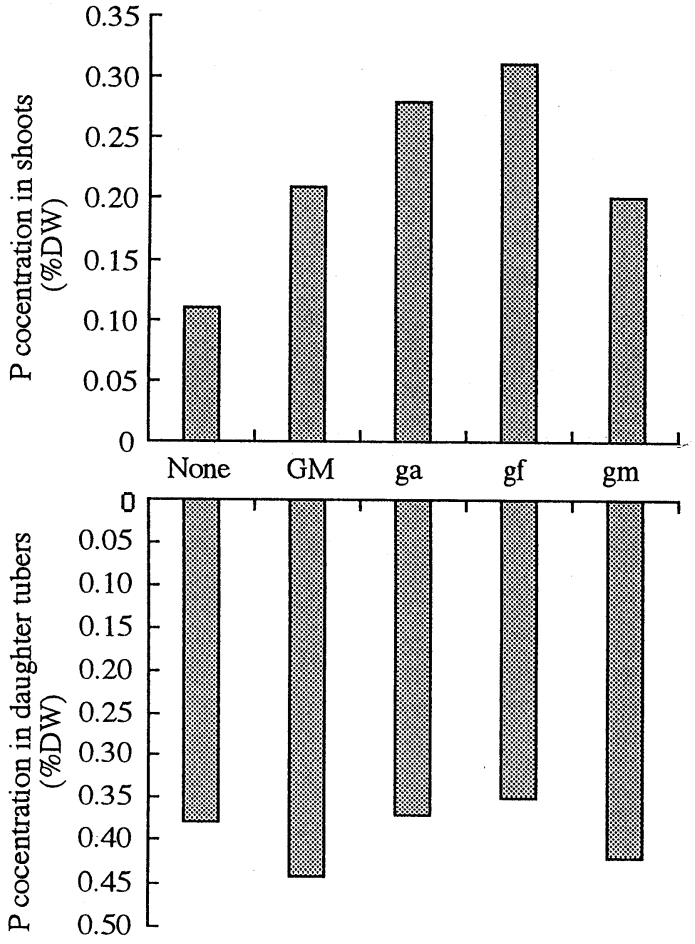

Fig. 5 Effect of AM fungus inoculation on phosphorus concentrations in sandersonia. None, noninoculated; GM, inoculated with Gigaspora margarita; ga, inoculated with Glomus aggregatum; gf, inoculated with Glomus fasciculatum, gm, inoculated with Glomus mosseae. Data were recorded 15 weeks after inoculation.

These facts suggest that AM fungal infection may improve both the plant growth and development of daughter tubers in plants derived from small tubers which have a poor ability to grow and flower. On the other hand, marble-shaped tubers formed in daughter tubers in our study, and their rate of formation was higher in AM fungus-infected plants than in noninoculated ones. Brundell and Reyngoud ${ }^{1)}$ found the same formation of marble-shaped tubers in daughter tubers, and showed no relationship between shoot growth and frequency of marble-shaped tuber formation. However, the reason for such frequent formation is unclear, and we were unable to discover it in this study.

In our study, $\mathrm{P}$ concentrations increased in $\mathrm{AM}$ fungus-infected plants, especially in shoots. We supposed that the promotion of flowering and the increase 
in the no. of flowers in AM fungus-infected plants were partially due to the growth enhancement caused by the $\mathrm{P}$ concentration increase in plants through $\mathrm{AM}$ fungal infection. On the other hand, no major difference occurred in $\mathrm{P}$ concentrations of daughter tubers among the treatments. We surmised that both the transportation of $\mathrm{P}$ from daughter tubers to shoots and the high consumption of $\mathrm{P}$ in daughter tuber development resulted in this lack of difference. Ijiro et $a l .^{6)}$ mentioned that in sandersonia, the size of planted tubers considerably influenced the shoot growth. However, the formation and development of daughter tubers were not strongly affected by the size of planted tubers but rather by shoot growth which is closely associated with photosynthesis. In this experiment, since size of the planted tubers was almostly the same, it is suggested that vigorous shoot growth in AM fungus-infected plants was mainly caused by the $\mathrm{P}$ concentration increase following infection, and that the promotion of transportation of photosynthate from shoots to tubers resulted in the prominent development of daughter tubers.

Although the AM fungal infection level was highest in GM and lowest in gm among the fungal species, vigorous development in daughter tubers occurred equally in both, suggesting that plant growth promotion might be not proportioned to the AM fungal infection level. On the other hand, Sutton ${ }^{15)}$ demonstrated that a 3-phase pattern in the fluctuation of AM fungus infection levels was found in soybean roots, and Matsubara et al. ${ }^{16)}$ also found such a fluctuation in Welsh onion roots inoculated with AM fungus. These findings make it difficult to estimate whether or not the infection of gm was continuously low during this experiment. Thus, further investigation might be needed to estimate the AM fungal infection level in each fungal species in sandersonia.

In our observation, irrespective of fungal species, AM fungal infection was exhibited only in lateral roots, and not in daughter tubers. It is reported that AM fungal infection occurred only in the lateral roots of several vegetable crops $^{12)}$ and in wild cherry ${ }^{17)}$. The same phenomenon was recognized in sandersonia. Pons et $a l .{ }^{17)}$ suggested that suberin in the roots affected AM fungal infection, and Matsubara and
Harada ${ }^{18)}$ indicated that the infection was influenced by pectic substances in roots. These results suggest that histological characteristics might be one of the reasons for the absence of infection in daughter tubers.

\section{References}

1) Brundell, D. J. and Reyngoud, J. L. : Observations on the development and culture of sandersonia. Acta Horticulturae, 177 : 439-447 (1985)

2) Eason, J. R. and Webster, D. : Development and senescence of Sandersonia aurantiaca (Hook.) flowers. Scientia Horticulturae, 63: 113-121 (1995)

3) Finne, J. F. and Staden, J. V. : Micropropagation and in vitro production of colchicine in sandersonia. Biotech. in Agri. and Forestry, 37 : 355-369 (1996)

4) Sumii, M. and Koike, N.: Characteristics of sandersonia and its forcing culture. Agri. and Hort., 69 : 305-310 (1994) (In Japanese)

5) Azuma, A.: Sandersonia. Farming and Hort., 51 : 53-55 (1996) (In Japanese).

6) Ijiro, Y., Mochiji, K. and Ogata, R. : Effects of tuber division on flowering and growth of daughter tubers in sandersonia, J. Japan. Soc. Hort. Sci., 66 (suppl. 1): 464-465(1997) (In Japanese)

7) Sawa, Y. and Kobayashi, K. : Studies on the cutting seed, immature seed and embryo culture in sandersonia, J. Japan. Soc. Hort. Sci., 60 (suppl. 2): 520-521 (1991) (In Japanese)

8) Finne, J. F. and Staden, J. V. : In vitro propagation of Sandersonia and Gloriosa, Plant cell, Tissue and organ culture, 19: 151-158(1989)

9) Raju, P. S., Clark, R. B., Ellis, J. R. and Maranville, J. W. : Effects of species of VA-mycorrhizal fungi on growth and mineral uptake of sorghum at different temperatures, Plant and Soil, 121 : 165-170 (1990)

10) Takenaga, J., Shioya, T. and Miyamoto, H. : The effect of vesicular- arbuscular mycorrhizal fungi and amount of fertilizer applied on the growth of cyclamen, J. Japan. Soc. Hort. Sci., 67 (suppl. 2): 451 (1998) (In Japanese)

11) Daft, M. J. and Okusanya, B. O. : Effect of endogone mycorrhiza on plant growth, V. Influence of infection on the multiplication of viruses in tomato, petunia and strawberry, New Phytol., 72 : 975-983 (1973)

12) Matsubara, Y., Harada, T. and Yakuwa, T. : Effect of arbuscular mycorrhizal fungi inoculation on seedling growth in several of vegetable crops, J. Jpn. Soc. Hort. Sci., 63: 619-628(1994) (In Japanese) 
13) Phillips, J. M. and Hayman, D. S. : Improved procedures for clearing roots and staining parasitic and vesicular-arbuscular mycorrhizal fungi for rapid assessment of infection, Trans. Br. Mycol. Soc., 55: 158-163(1970)

14) Matsubara, Y. and Harada, T. : Effect of arbuscular mycorrhizal fungus infection on growth and mineral nutrient content of Asparagus officinalis L. seedlings, J. Jpn. Soc. Hort. Sci., 65: 303-309 (1996) (In Japanese)

15) Sutton, J. C. : Development of vesicular-arbuscular mycorrhizae in crop plants, Can. J. Bot., 51 : 2487-2493 (1973)

16) Matsubara, Y., Harada, T. and Yakuwa, T. : Effect of inoculation density of vesicular-arbus- cular mycorrhizal fungal spores and addition of carbonized material to bed soil on growth of Welsh onion seedlings, J. Jpn. Soc. Hort. Sci., $64: 549-554$ (1995) (In Japanese)

17) Pons, F., Gianinazzi-Pearson, V., Gianinazzi, S. and Navatel, J. C. : Studies of VA mycorrhizae in vitro; mycorrhizal synthesis of axenically propagated wild cherry(Prunus avium L.) plants, Plant and Soil, 71 : 217-221 (1983)

18) Matsubara, Y. and Harada, T. : Relation between pectic substances and arbuscular mycorrhizal fungus infection in three vegetable crops, J. Jpn. Soc. Hort. Sci., 67: 180-184(1998)

サンダーソニアの生長に及ぼすアーバスキュラー菌根菌接種の影響

松原陽一・櫻井聡子

岐阜大学農学部 干 501-1193 岐阜市柳戸 1-1 